the optical trade and assisted by a less expensive and shorter training, take over the entire refraction work of the country. For economic reasons all clinic work would fall to them. Within a short time eye surgeons would revert to the old arrangement where eye, ear, nose and throat work was combined or eye and skin, eye and general practice or eye and general surgery. There would not be enough eye men to staff general hospitals. The dispensing opticians would have to employ "trained" sight testers and eye doctors would have to do their own dispensing. Eventually there might be no more than 50 whole time eye specialists in the country.

We are being well represented by the Ophthalmic Group of the British Medical Association and by the Association of British Ophthalmologists, working in close contact with each other. It is of great importance that all eye men should assist these two bodies at this time and in any case bide loyally by their decisions.

Yours faithfully,

J. Myles Bickerton,

Senior Ophthalmic Surgeon, King's College Hospital.

Late temp. Wing-Comdr., R.A.F.V.R.

\title{
OBITUARY
}

\section{PERCY FLEMMING}

THE death of Mr. Percy Flemming, Emeritus Professor of Ophthalmic Medicine and Surgery at University College, on December 19, 1941, at the age of 78 years was briefly announced in our last issue. A Londoner by birth, he was a product of University College, for his preliminary education was received at University College School and he proceeded to University College Hospital for his medical training; he was one of whom the School and Hospital were justly proud. Having taken the conjoint diplomas in 1885 he obtained his M.B. London in 1887 with the University Scholarship in medicine and honours in most of the other subjects. He took the M.D. with gold medal in 1888 and the F.R.C.S.Eng. in 1889 after a brilliant academic career.

Flemming succeeded to the vacancy in the ophthalmic department at University College Hospital caused by the resignation of Marcus Gunn. His chief was Sir John Tweedy and on the latter's retirement he advanced to the senior post. In 1900 he was elected to the staff at Moorfields and served his full time becoming consulting surgeon to both institutions. He was also a Fellow of University College. 
Flemming was a brilliant ophthalmologist but was not a profuse writer on his special subject. His retiring nature and habitual modesty perhaps made him not quite so well known outside the hospital as he deserved to be. Those who knew him appreciated his profound knowledge of his subject and his ever ready help in consultation.

Flemming had a second string to his life's interests, in archaeology and the history of London on which he was a recognised authority. Many of the older members of the Ophthalmological Society will remember an informal lecture which he gave on the neighbourhood of Moorfields Hospital more than 20 years ago at an annual congress. So far as we know this lecture was never published, but he printed for private circulation an address which he gave, on late mediæval London from a medical point of view, to University College Hospital Medical Society. And he was the author of a paper on the monastic infirmaries, particularly that of Westminster Abbey. He was elected F.S.A. in 1931.

When the writer of this note was preparing memoirs of past members of the staff of Moorfields for the British Masters of Ophthalmology series in this Journal he approached Mr. Flemming who most generously sent him notes concerning these men which he had made for his own purposes from the minutes of the hospital. This was characteristic of him for his help was always freely given. $\mathrm{He}$ was keenly interested in ophthalmic nursing and was largely concerned, together with Marcus Gunn, in founding the training school for nurses at Moorfields.

Mr. Flemming practised at 70 Harley Street, where his wife, also M.D.Lond. had her plate on the door. Mrs. Flemming died last year and the sympathy of the ophthalmic profession will go out to their two sons, one of whom is on the surgical staff of University College Hospital.

\section{Sir John Parsons writes :-}

Percy Flemming was one of those modest and retiring people whose lifework is done so unostentatiously that its merits are liable to be underestimated or wholly ignored. My intimate association with him commenced in 1899 when we were both clinical assistants to Sir John Tweedy at Moorfields. Shortly afterwards he was appointed ophthalmic surgeon to University College Hospital and I became his clinical assistant there and at Moorfields. Still later I became his colleague at both hospitals, and after our retirement from hospital work we served together on a Committee for the Prevention of Blindness. It is not too much to say that I owe more to his help and encouragement in ophthalmology than to anyone else. In this respect I am by no means alone; for one of 
Flemming's joys in life was helping lame dogs over stiles. He was a born teacher, and his patience and perseverance in imparting his profound knowledge, whether of anatomy, ophthalmology (both medical and surgical), or archaeology. (especially of London), were illimitable. In all these subjects he was a master. In ophthalmo$\log y$ he was a first-class clinician and a good operator. He was no narrow specialist; for his proficiency in anatomy and medicine stimulated his special interest in the ocular signs of general disease, such as thrombosis of the cavernous sinus, with valuable results. It is much to be regretted that his contributions to ophthalmic literature were comparatively few; for only his colleagues and students are fully aware of the extent and scientific accuracy of his clinical work. He was deeply interested in the social and preventive aspects of ophthalmology, and the admirable report of the Departmental Coinmittee on the Partially Blind was largely due to his untiring energy and level-headed judgment. It is not surprising that he was specially devoted to his alma mater, University College, for he was an alumnus of University College School, a Fellow of the College, and the last Professor of Ophthalmology in it before its absorption in the University of London, as well as Ophthalmic Surgeon to University College Hospital. Whilst most ophthalmic surgeons who have had the honour of being members of the staff of Moorfields have become attached to it with love and veneration there can be no doubt that Flemming, though not wanting in the same sentiments, remained specially devoted to his first love, and no one was more loyal to the great traditions of University College Hospital than he.

\section{NOTES}

Death As we go to press we learn with much regret of the death of Mr. Gray Clegg, late of Manchester. We hope to publish a memoir of him in our next number.

Honour

Among the New Year's honours we are Cruickshank, I.M.S., who receives the C.I.E.

glad to see the name of Lieut.-Col. M. M.

Special Notice

WE are asked by the Ministry of Information to state that the fact that goods made of raw materials in short supply owing to war conditions are advertised in this journal should not be taken as an indication that they are necessarily available for export. 